\title{
Risk of Type 2 Diabetes Among the Pakistani Population: Results of a Cross-sectional Survey
}

\author{
Fauzia H. Mohammad ${ }^{1}$, Kashmira Nanji ${ }^{2}$ \\ 1. Family Medicine, The Aga Khan University, Karachi, PAK 2. Epidemiology and Public Health, The Aga Khan \\ University, Karachi, PAK
}

Corresponding author: Kashmira Nanji, kashmira.nanji@gmail.com

\begin{abstract}
Introduction

Diabetes is a global issue. The aim of this study was to identify the high-risk population and factors associated with the future development of type 2 diabetes mellitus (T2DM).
\end{abstract}

\section{Methods}

A cross-sectional study was conducted in the Family Medicine clinics of a tertiary care hospital in Karachi, Pakistan, from July 2016 to February 2017. Patients or patient care attendants aged 21 to 85 years visiting the clinics were included. Individuals with known diabetes or with serious comorbid conditions were excluded. A total of 600 participants were consecutively approached. QDiabetes (an online diabetes risk calculator) was used to measure the risk of developing T2DM. IBM SPSS Statistics for Windows, Version 19.0 (IBM Corp., Armonk, NY) was used for data analysis.

\section{Results}

Information from a total of 522 participants was included in the final analysis. Roughly $53 \%$ of them were between 25 and 44 years of age. There was a predominance of females (63\%). Thirty-eight percent of patients were at high-risk. The factors associated with high risk of T2DM were as follows: age 65 years or greater (Relative risk [RR]: 5.81; 95\% confidence interval [CI]: 2.01 to 16.76); female (RR: 1.86 ; $95 \%$ CI: 1.05 to $3.28, p=0.03$ ); a past history of hypertension (RR: $5.11 ; 95 \%$ CI: 2.49 to 10.49 ); a family history of diabetes (RR: 9.76 ; $95 \%$ CI: 5.49 to 13.35 ).

\section{Conclusion}

Controlling glucose levels and preventing hyperglycemia is a challenging task due to the increasing trend of a sedentary lifestyle and changes in dietary patterns. Counseling should be provided to caregivers and highrisk patients on the prevention of T2DM including lifestyle modifications.

Received 07/06/2018

Review began 07/26/2018

Review ended 08/11/2018

Published 08/14/2018

๑) Copyright 2018

Mohammad et al. This is an open access article distributed under the terms of the Creative Commons Attribution License CC-BY 3.0., which permits unrestricted use, distribution, and reproduction in any medium, provided the original author and source are credited.
Categories: Family/General Practice, Gastroenterology, Public Health

Keywords: $\mathrm{t} 2 \mathrm{dm}$, factors, predictors, pakistan

\section{Introduction}

Diabetes is a global issue. Type 2 diabetes mellitus (T2DM) is the most common form of diabetes. Globally, $80 \%$ to $90 \%$ of diabetes cases are T2DM [1]. According to the International Diabetes Federation (IDF), it is estimated that almost 415 million people had diabetes worldwide in 2015, and by the year 2040, the number is expected to rise to 642 million with more than $80 \%$ of these cases in developing countries [2]. The number of deaths due to diabetes was five million in 2015 [2].

The IDF has projected that by the year 2025, 11.5 million people in Pakistan will be living with diabetes, placing Pakistan fifth on the IDF ranking of diabetes populations [3,4]. The increasing prevalence of diabetes is mainly attributed to population growth, aging, urbanization, and the increasing prevalence of obesity and physical inactivity [5-7].

Almost 200 million people with diabetes are undiagnosed and are, therefore, at a greater risk of developing complications such as kidney failure, blindness, amputations, and stroke. These complications may be prevented by identifying the high-risk population [8,9]. In many cases, T2DM can be prevented by adopting a healthy lifestyle.

Therefore, identifying high-risk populations (obese patients, positive family history of diabetes, etc.) is imperative in saving lives and can assist in preventing or significantly delay devastating diabetes-related complications [10]. The aim of this study was to identify the high-risk population and the factors associated with future development of T2DM. 


\section{Materials And Methods}

A cross-sectional study was conducted in Family Medicine clinics affiliated with a tertiary care teaching hospital in the private sector in Karachi, Pakistan, from July 2016 to February 2017. These clinics were included because they cater to the health needs of people from different socioeconomic strata, providing the study a sample from a diverse population.

Patients or their attendants, 21 to 85 years of age, were invited to participate in the study. However, individuals with known diabetes or suffering from serious comorbid conditions such as cancer, advanced heart failure, or other comorbidities, were excluded. A total of 600 participants were approached to take part in this study. Written informed consent was obtained from all participants, and the study was conducted in accordance with the Declaration of Helsinki.

A previously validated structured questionnaire was used for data collection. The first section was composed of demographic details while the second section included the online calculator QDiabetes [11] to measure the absolute risk of developing T2DM. It has been validated and is widely used in various studies. This online calculator uses factors such as age, sex, smoking status, family history of diabetes, history of cardiovascular disease, history of hypertension, and body mass index (BMI) to calculate the risk of developing T2DM. Before commencement of the study, data collectors were trained for obtaining consent and filling up of the forms.

We have categorized relative risk (RR) into two groups. An RR less than one was labeled as low while an RR of more than one was labeled as high-risk of developing T2DM.

Asian BMI cutoffs were used in this study. The categories of BMI for Asians are as follows: less than 18.5 $\mathrm{kg} / \mathrm{m}^{2}$ (underweight); 18.5 to $23 \mathrm{~kg} / \mathrm{m}^{2}$ (normal); 23 to $27.5 \mathrm{~kg} / \mathrm{m}^{2}$ (overweight); and $27.5 \mathrm{~kg} / \mathrm{m}^{2}$ or higher (obese).

Data were entered and analyzed in IBM SPSS Statistics for Windows, Version 19.0 (IBM Corp., Armonk, NY). The analysis was performed in two stages (i.e., descriptive and inferential). The frequencies and proportions of all the variables were reported in the descriptive analysis. A Pearson chi-square test was applied to compare low-risk and high-risk individuals. A multivariable Cox regression analysis was used to study the independent association of variables with the presence of a high-risk of diabetes. The RR with 95\% confidence intervals (CIs) was estimated.

\section{Results}

A total of 600 participants were approached. Of those, 522 gave consent and were included in the final analysis, yielding a response rate of $87 \%$. Table 1 presents the baseline characteristics of the study participants. About $53 \%$ of the participants were between 25 and 44 years of age. There was a predominance of women in the study sample (63\%). Slightly more than two-fifths (42\%) of the participants had a family history of diabetes while $24 \%$ had a history of hypertension. About $36 \%$ of the participants were obese, and $26 \%$ were morbidly obese. Approximately $38 \%$ of the participants were calculated to have a high risk of diabetes in the next 10 years. 


\section{Cureus}

\begin{tabular}{|c|c|c|}
\hline Variables & Frequency & Percentage \\
\hline \multicolumn{3}{|l|}{ Age } \\
\hline $25-44$ years & 279 & 53 \\
\hline 45-64 years & 191 & 36 \\
\hline$>65$ years & 52 & 10 \\
\hline \multicolumn{3}{|l|}{ Gender } \\
\hline Male & 192 & 37 \\
\hline Female & 330 & 63 \\
\hline \multicolumn{3}{|l|}{ Smoking } \\
\hline Yes & 34 & 6 \\
\hline \multicolumn{3}{|c|}{ Family History of Diabetes } \\
\hline Yes & 220 & 42 \\
\hline \multicolumn{3}{|c|}{ Past History of Hypertension } \\
\hline Yes & 124 & 23.7 \\
\hline \multicolumn{3}{|c|}{ Past History of Cerebrovascular Accident (CVA) } \\
\hline Yes & 7 & 1.3 \\
\hline \multicolumn{3}{|c|}{ Body Mass Index (BMI) } \\
\hline Underweight & 16 & 3 \\
\hline Normal weight & 105 & 20 \\
\hline Overweight & 76 & 14 \\
\hline Obese & 325 & 63 \\
\hline \multicolumn{3}{|c|}{ Future Risk of Diabetes } \\
\hline Low risk & 325 & 62 \\
\hline High risk & 197 & 38 \\
\hline
\end{tabular}

TABLE 1: Baseline characteristics of study participants $(n=522)$.

Seventy-four percent of men and $55 \%$ of women were at a low risk of developing diabetes in the future (Table 2). A past history of hypertension among men (31\%) and women (35\%) was predictive of being at high risk. 


\section{Cureus}

\begin{tabular}{|c|c|c|c|c|}
\hline \multirow{2}{*}{$\begin{array}{l}\text { Variables } \\
\text { Parameter } n=522\end{array}$} & \multicolumn{2}{|l|}{ Men } & \multicolumn{2}{|l|}{ Women } \\
\hline & Low Risk $(n=143)$ & High Risk $(n=49)$ & Low Risk $(n=182)$ & High Risk $(n=148)$ \\
\hline \multicolumn{5}{|l|}{ Age } \\
\hline 25 -44 years (\%) & $72(50.3)$ & $30(61.2)$ & $98(53.8)$ & 79 (53.4) \\
\hline 45-64 years (\%) & $51(35.7)$ & $17(34.7)$ & $61(33.5)$ & $62(41.9)$ \\
\hline$>65$ years $(\%)$ & $20(14.0)$ & $2(4.1)$ & $23(12.6)$ & $7(4.7)$ \\
\hline$P$ value & 0.13 & & 0.028 & \\
\hline \multicolumn{5}{|l|}{ Current Smokers } \\
\hline Yes (\%) & $22(15.4)$ & $10(20.4)$ & $1(0.5)$ & $1(0.7)$ \\
\hline$P$ value & 0.41 & & 0.883 & \\
\hline \multicolumn{5}{|c|}{ Family History of Diabetes } \\
\hline Yes (\%) & $29(20.3)$ & $32(65.3)$ & $61(33.5)$ & $98(66.2)$ \\
\hline$P$ value & 0.000 & & 0.000 & \\
\hline \multicolumn{5}{|c|}{ Past History of Hypertension } \\
\hline Yes (\%) & $26(18.2)$ & $15(30.6)$ & $32(17.6)$ & $51(34.5)$ \\
\hline$P$ value & 0.06 & & 0.000 & \\
\hline \multicolumn{5}{|c|}{ Past History of Cerebrovascular Accident (CVA) } \\
\hline Yes (\%) & --- & $5(10.6)$ & $2(1.1)$ & --- \\
\hline$P$ value & 0.185 & & 0.201 & \\
\hline \multicolumn{5}{|c|}{ Body Mass Index (BMI) } \\
\hline Under weight (\%) & $8(5.6)$ & --- & $8(4.4)$ & --- \\
\hline Normal weight (\%) & $54(37.8)$ & --- & $51(28.0)$ & --- \\
\hline Overweight (\%) & $28(19.6)$ & $1(2.0)$ & $47(25.8)$ & --- \\
\hline Obese (\%) & $53(37)$ & $48(98)$ & $76(42)$ & $148(100)$ \\
\hline$P$ value & 0.000 & & 0.000 & \\
\hline
\end{tabular}

TABLE 2: Gender-specific risk of diabetes among study participants $(n=522)$.

Participants who were 65 years or older (RR: 5.81; 95\% CI: 2.01 to 16.76), were women (RR: 1.86; 95\% CI: 1.05 to 3.28 ), or had a past history of hypertension (RR: 5.11 ; $95 \%$ CI: 2.49 to 10.49 ) were significantly more likely to have a predicted high risk of future T2DM (Table 3). 


\section{Cureus}

\begin{tabular}{|c|c|c|c|}
\hline Variables & Unadjusted Relative Risk (95\% Cl) & Adjusted Relative Risk (95\% CI) & $P$ value \\
\hline Age $45-64$ years & $3.06(1.43-6.53)$ & $4.90(1.76-13.61)$ & \multirow{2}{*}{0.004} \\
\hline Age $\geq 65$ years & $3.37(1.55-7.30)$ & $5.81(2.01-16.76)$ & \\
\hline Female & $2.37(1.60-3.50)$ & $1.86(1.05-3.28)$ & 0.03 \\
\hline Past history of hypertension & $2.31(1.53-3.49)$ & $5.11(2.49-10.49)$ & $<0.001$ \\
\hline Family history of diabetes & $5.06(3.45-7.43)$ & $9.76(5.49-13.35)$ & $<0.001$ \\
\hline High-risk BMI & $5.26(4.93-13.99)$ & $8.97(4.12-12.51)$ & $<0.001$ \\
\hline
\end{tabular}

TABLE 3: Factors associated with high risk of diabetes among study participants.

Cl: Confidence interval; BMI: Body mass index.

\section{Discussion}

In our study, 38\% of the study participants were at a high risk of developing diabetes. Moreover, factors such as being older than 65 years of age, female, obese, having a family history of diabetes, or a personal history of hypertension are predictors of developing diabetes in future. Our study results are congruent with previous studies, and, hence, the control and prevention of these factors are essential, particularly among high-risk patients, to prevent the future occurrence of T2DM in this population.

Several studies suggest that hypertension is more common in people with diabetes than in the general population $[12,13]$. This is consistent with our findings, and suggests that a history of hypertension is highly associated with developing diabetes in the future (RRadj: 5.11; 95\% CI: 2.49 to 10.49).

A 10-year cohort study revealed that, when compared with their same-sex peers, patients with a BMI greater than 25 were approximately 20 times more likely to develop diabetes (RR: 17.0 for women; RR: 23.4 for men) [14]. This is consistent with the results of the current study where having a BMI of more than 25 increased the risk of developing diabetes approximately nine-fold.

Evidence suggests that smoking increases the risk of diabetes many times [15,16]. A meta-analysis conducted on 88 studies concluded that there was a dose-response relationship for current smoking and diabetes risk: the RRs were 1.34 for moderate and 1.57 for heavy smokers [16]. Public health efforts to reduce smoking could have a substantial effect on the worldwide burden of T2DM. In this study, $0.6 \%$ of the respondents were smokers. Since smoking is generally considered as socially unacceptable, there is a possibility of underreporting by the study participants.

A history of cardiovascular disease (CVD) has been reported by several studies to be associated with a higher risk of developing diabetes $[17,18]$. In this study, however, a history of CVD did not have a significant association with the calculated future risk of diabetes. This may be because only a small number of study participants had CVD (1.3\%).

Evidence from Pakistan suggests that women have a higher risk of poor glycemic control resulting in further complications $[19,20]$. The current study also found that females had a higher risk of developing T2DM (RR: 1.86; $95 \%$ CI: 1.05 to 3.28). In Pakistan, the health of women is compromised as they are not empowered to make many of their own decisions and in some cases are not allowed to go outside their homes without a male member of the household [21]. These issues leave them more exposed to a sedentary lifestyle and obesity.

This study had certain limitations. As it was a cross-sectional study, we cannot comment on the causal associations of the factors with the risk of T2DM. Therefore, cohort studies are needed to determine the causality between the factors that increases the risk of DM. In this study, we estimated the risk of future DM from a pre-designed online calculator, which might have not included all the confounders, this may have led to over or underestimation of the study results. Moreover, we did not check glycosylated hemoglobin, the best marker for the identification of individuals with undiagnosed diabetes, as we could not arrange funds for the laboratory work. Moreover, this study was conducted in the primary clinics of a tertiary care hospital, so the results may not be generalizable to the general population.

\section{Conclusions}

Controlling glucose levels and preventing hyperglycemia is a challenging task due to increasing trends 
towards a sedentary lifestyle and changes in dietary patterns. Nonetheless, this study serves as a basis for future interventional studies to reduce the immense future burden of T2DM. Based on our study findings, we recommend that counseling should be provided to caregivers and high-risk patients regarding T2DM prevention and lifestyle modifications including increased physical activity and smoking cessation. Moreover, nutrition intervention should be tailored according to each patient's age, lipid levels, and medical conditions.

\section{Additional Information \\ Disclosures}

Human subjects: Consent was obtained by all participants in this study. Animal subjects: All authors have confirmed that this study did not involve animal subjects or tissue. Conflicts of interest: In compliance with the ICMJE uniform disclosure form, all authors declare the following: Payment/services info: All authors have declared that no financial support was received from any organization for the submitted work. Financial relationships: All authors have declared that they have no financial relationships at present or within the previous three years with any organizations that might have an interest in the submitted work. Other relationships: All authors have declared that there are no other relationships or activities that could appear to have influenced the submitted work.

\section{References}

1. Global report on diabetes. (2016). Accessed: May 8, 2018: http://apps.who.int/iris/bitstream/handle/10665/204871/9789241565257_eng.pdf.

2. Ogurtsova K, Fernandes DR, Huang Y, et al.: IDF diabetes atlas: global estimates for the prevalence of diabetes for 2015 and 2040. Diabetes Res Clin Pract. 2017, 128:40-50. 10.1016/j.diabres.2017.03.024

3. Guariguata L, Whiting DR, Hambleton I, Beagley J, Linnenkamp U, Shaw JE: Global estimates of diabetes prevalence for 2013 and projections for 2035. Diabetes Res Clin Pract. 2014, 103:137-149. 10.1016/j.diabres.2013.11.002

4. Whiting DR, Guariguata L, Weil C, Shaw J: IDF diabetes atlas: global estimates of the prevalence of diabetes for 2011 and 2030. Diabetes Res Clin Pract. 2011, 94:311-321. 10.1016/j.diabres.2011.10.029

5. Basit A, Riaz M, Fawwad A: Improving diabetes care in developing countries: the example of Pakistan . Diabetes Res Clin Pract. 2015, 107:224-232. 10.1016/j.diabres.2014.10.013

6. Martin-Timon I, Sevillano-Collantes C, Segura-Galindo A, Del Canizo-Gomez FJ: Type 2 diabetes and cardiovascular disease: have all risk factors the same strength?. World J Diabetes. 2014, 5:444-470. 10.4239/wjd.v5.i4.444

7. Balk EM, Earley A, Raman G, Avendano EA, Pittas AG, Remington PL: Combined diet and physical activity promotion programs to prevent type 2 diabetes among persons at increased risk: a systematic review for the community preventive services task force. Ann Intern Med. 2015, 163:437-451. 10.7326/M15-0452

8. Stratton IM, Adler AI, Neil HA, et al.: Association of glycaemia with macrovascular and microvascular complications of type 2 diabetes (UKPDS 35): prospective observational study. BMJ. 2000, 321:405-412. 10.1136/bmj.321.7258.405

9. Courcoulas AP, Belle SH, Neiberg RH, et al.: Three-year outcomes of bariatric surgery vs lifestyle intervention for type 2 diabetes mellitus treatment: a randomized clinical trial. JAMA Surg. 2015, 150:931940. 10.1001/jamasurg.2015.1534

10. Inzucchi SE, Bergenstal RM, Buse JB, et al.: Management of hyperglycemia in type 2 diabetes, 2015: a patient-centered approach: update to a position statement of the American Diabetes Association and the European Association for the Study of Diabetes. Diabetes Care. 2015, 38:140-149. 10.2337/dc14-2441

11. QDiabetes 2018 risk calculator. (2018). Accessed: May 8, 2018: https://qdiabetes.org/2018/.

12. Ansari RM, Hosseinzadeh H, Harris M, Zwar N: Conceptual model of diabetes self-management for middleaged population of rural area of Pakistan. Int J Diabetes Res. 2017, 6:68-72.

13. Hayden MR, Sowers JR: Hypertension in type 2 diabetes mellitus. Insulin. 2006, 1:22-37. 10.1016/S15570843(06)80005-9

14. Field AE, Coakley EH, Must A, et al.: Impact of overweight on the risk of developing common chronic diseases during a 10-year period. Arch Intern Med. 2001, 161:1581-1586. 10.1001/archinte.161.13.1581

15. Memon HNA, Ali Z, Shaikh MK, Dad M, Buhari S, Baloch ZAQ: Association of type 2 diabetes mellitus with smoking at tertiary care hospital. Indo Am J Pharm Sci. 2017, 4:765-770.

16. Akter S, Goto A, Mizoue T: Smoking and the risk of type 2 diabetes in Japan: a systematic review and metaanalysis. J Epidemiol. 2017, 27:553-561. 10.1016/j.je.2016.12.017

17. Arshad S, Tahir S, Tahir B, et al.: Risk factors associated with diabetes mellitus in local population of Lahore, Pakistan. Glob J Health Sci. 2017, 9:42-51.

18. Zia A, Bhatti A, Jalil F, et al.: Prevalence of type 2 diabetes-associated complications in Pakistan . Int J Diabetes Dev Ctries. 2016, 36:179-188. 10.1007/s13410-015-0380-6

19. Alamgir MA, Javid RA, Hameed A, Mustafa I: Gender difference in components of metabolic syndrome among patients of type 2 diabetes. Pakistan J Med Sci. 2015, 31:886-890. 10.12669/pjms.314.6714

20. Siddiqui FJ, Avan BI, Mahmud S, Nanan DJ, Jabbar A, Assam PN: Uncontrolled diabetes mellitus: prevalence and risk factors among people with type 2 diabetes mellitus in an urban district of Karachi, Pakistan. Diabetes Res Clin Pract. 2015, 107:148-156. 10.1016/j.diabres.2014.09.025

21. Ashwell M, Gibson S: Waist-to-height ratio as an indicator of 'early health risk': simpler and more predictive than using a 'matrix' based on BMI and waist circumference. BMJ Open. 2016, 6:e010159. 10.1136/bmjopen-2015-010159 